\title{
Host selection by Platypus quercivorus (Murayama) (Coleoptera: Platypodidae) before and after flying to trees
}

\author{
Michimasa Yamasaki ${ }^{1, *}$ and Kazuyoshi FutaI ${ }^{2}$ \\ ${ }^{1}$ Laboratory of Forest Biology, Division of Forest and Biomaterials Science, Graduate School of Agriculture, Kyoto University; \\ Kyoto 606-8502, Japan \\ ${ }^{2}$ Laboratory of Environmental Mycoscience, Division of Environmental Science and Technology, Graduate School of Agriculture, \\ Kyoto University; Kyoto 606-8502, Japan
}

(Received 20 August 2007; Accepted 21 December 2007)

\begin{abstract}
The ambrosia beetle Platypus quercivorus causes mass mortality of fagaceous trees throughout Japan. Previous studies demonstrated low levels of $P$. quercivorus attack on both thinner trees and re-attacked trees with previous infection history. To determine the causes of the low levels of attack on these trees, the patterns of attack by P. quercivorus were investigated in 35 Quercus crispula trees for two consecutive years. Logistic regression analysis indicated a significant positive effect of tree size on the probability of male beetle flying to trees, although previous infection history was not selected as an explanatory variable in the model. Tree size and previous infection history exhibited significant positive and negative effects, respectively, when both were selected as explanatory variables in a model predicting the probability of male beetle boring holes in trees. These results suggest that $P$. quercivorus disregards thinner trees, and flies away from trees with previous infection history after approaching.
\end{abstract}

Key words: Host selection; mass mortality of fagaceous trees; Platypus quercivorus; previous infection history; Quercus crispula

\section{INTRODUCTION}

The mass mortality of fagaceous trees in Japanese forests has recently become a serious problem (Ito and Yamada, 1998; Kobayashi and Ueda, 2005). The Japanese oak, Quercus crispula, is strongly affected by disease-driven mass mortalities on Honshu Island, Japan (Shiomi and Osaki, 1997; Nishigaki et al., 1998). The disease is caused by the ambrosia beetle, Platypus quercivorus (Murayama) (Coleoptera: Platypodidae), which attacks apparently healthy trees and transports a pathogenic fungus, Raffaelea quercivora, from tree to tree (Ito et al., 1998; Saito et al., 2001; Kubono and Ito, 2002; Kinuura and Kobayashi, 2006). Tree species vary in mortality rate when attacked by $P$. quercivorus. For example, Q. serrata exhibits lower susceptibility to the disease than $Q$. crispula (Shiomi and Osaki, 1997; Inoue et al., 2000; Kobayashi and Hagita, 2000; Kobayashi and Shi- bata, 2001; Kobayashi and Ueda, 2001), probably because of active sap exudation in Q. serrata (Kobayashi et al., 2004). The low susceptibility of $Q$. salicina can be explained in part by the low proportion of male $P$. quercivorus that bored holes in trees after flying to them (Yamasaki et al., 2007).

Our research focused on the mechanisms driving intraspecific variation in levels of attack by $P$. quercivorus. Previous studies have demonstrated that tree size and previous infection history are factors associated with intraspecific variation in the level of attack. Thinner trees exhibited lower densities of beetle holes (Kobayashi and Shibata, 2001; Kobayashi and Ueda, 2001), and trees with previous infection history also exhibited lower densities of beetle holes than those attacked for the first time (Inoue et al., 2000; Kobayashi, 2000). These studies indicate that, at some point during the process of attack, $P$. quercivorus discriminates among host trees on the basis of size and previous infection

\footnotetext{
* To whom correspondence should be addressed at: E-mail: risei@kais.kyoto-u.ac.jp
} DOI: 10.1303/aez.2008.249 
history; however, the specific timing of these decisions by $P$. quercivorus has not been determined. Therefore, we hypothesized that the following two potential scenarios are responsible for the low levels of attack by $P$. quercivorus on thinner trees and trees with previous infection history: (1) P. quercivorus selects host trees before flying to them, i.e., the beetles disregard thinner trees and/or trees with previous infection history; and (2) P. quercivorus selects host trees after flying to them, i.e., the beetles leave thinner trees and/or trees with previous infection history after flying to them.

To differentiate between these two hypotheses, we investigated the patterns of attack by $P$. quercivorus on 35 Q. crispula trees for two consecutive years. We monitored the flying activity of $P$. quercivorus to examine host selection before flying to trees (Hypothesis 1). For trees to which P. quercivorus flew, we estimated the density of beetle holes to investigate host selection after flying to trees (Hypothesis 2). We used a logistic regression model to predict the probability of male beetles flying to trees and the probability of male beetles boring holes in trees, using tree size and previous infection history as explanatory variables. We also discuss likely proximate causes for host selection by $P$. quercivorus.

\section{MATERIALS AND METHODS}

The study was conducted in 2004-2005 at the Ashiu Forest Research Station, Field Science Education and Research Center, Kyoto University, located in the northeastern part of Kyoto Prefecture, Japan $\left(35^{\circ} 18^{\prime} \mathrm{N}, 135^{\circ} 43^{\prime} \mathrm{E}\right)$. The research station is located at an altitude of $355-959 \mathrm{~m}$, and the study was conducted in a $25 \times 25-\mathrm{m}$ study plot established on a south-facing slope of a secondary forest, at an altitude of approximately $500 \mathrm{~m}$.

In June 2004, we measured the diameter at breast height $(\mathrm{DBH} ; 130 \mathrm{~cm})$ of all Q. crispula trees inside the plot and selected 35 trees with DBH over $5 \mathrm{~cm}$ for the study. To calculate the surface area of the trunk up to $50 \mathrm{~cm}$ above ground, the tree perimeters at $50 \mathrm{~cm}$ aboveground and at the root collar were measured for each tree at the beginning of the study. In addition, each tree was examined for any signs of attack by P. quercivorus, but no beetle holes were found in the 35 trees.

The patterns of attack by $P$. quercivorus on the
35 trees were followed for 2 years, from early July to late October 2004, and from late June to early November 2005. The abundance of flying populations of $P$. quercivorus was measured using sticky paper traps (Kobayashi and Hagita, 2000; Ueda and Kobayashi, 2001b). Two strips of sticky paper $(4 \times 50 \mathrm{~cm}$ each; Kamikiri-hoihoi, Earth Chemical Co., Ltd., Tokyo) were attached to opposite sides, upper and lower sides of the slope, on each tree trunk. Sticky papers were oriented longitudinally, from the ground level up to $50 \mathrm{~cm}$ above ground. The number of male $P$. quercivorus trapped on each strip was counted at 1 -week intervals. The number of male $P$. quercivorus and the area of sticky paper were used to calculate the number of male beetles that flew to each tree per $100 \mathrm{~cm}^{2}$ (number of flying male beetles, NFM) for each 1-week interval.

In the case of Platypodidae, male beetles first fly to their host trees and bore holes in them (Kirkendall, 1983); therefore, we estimated the number of male $P$. quercivorus which flew to the trees in this study, by counting male beetles trapped on each sticky sheet.

We also counted the number of beetle holes on the surface of each tree trunk, up to a height of $50 \mathrm{~cm}$ above ground but outside the area covered with two strips of sticky paper. Double-counting of beetle holes was avoided by using colored pushpins to mark previously counted beetle holes. The area of the observed trunk surface of each tree was calculated by assuming that the shape of the subject trunk surface was a trapezoid. The number of beetle holes and the area of the subject trunk surface were used to calculate the density of newly bored holes per $100 \mathrm{~cm}^{2}$ (density of holes, DH) for each 1 -week interval.

NFM and DH were assessed at 1-week intervals with the exception of the period from September to November 2005, when data were collected at 1month intervals. For consistent figure presentation, NFM data from this period were divided by four to obtain 1-week averages.

Cumulative values of NFM for each tree were compared between years with respect to the presence or absence of beetle holes in 2004. We conducted Wilcoxon signed-rank tests using PROC UNIVARIATE (SAS, 2004), as we could not assume normality and homogeneity of variances for these data.

Cumulative values of NFM for each tree in each 
year were converted to binary data, i.e., " 0 " for $\mathrm{NFM}=0$ and " 1 " for NFM $>0$. We used a generalized linear mixed model with a logit link function and binomial error structure to test the effects of explanatory variables on the binary NFM data. The model included tree size (DBH) and previous infection history (" 0 " for no infection in the previous year and " 1 " for infection in the previous year) as fixed effects. Data from each of the 35 trees within each year were pooled for analysis, and year was included in the model as a random effect. Analysis was conducted using PROC GLIMMIX (SAS, 2004). The variance estimate of the random effect (year) was not significantly different from zero $(p=$ $0.4669)$. Thus, we repeated the logistic regression analysis using only the fixed effects to predict NFM (binary data). Two explanatory variables, DBH and previous infection history, were included in the model built by stepwise selection using PROC LOGISTIC (SAS, 2004).

For individual tree data of NFM $>0$ ( 24 trees in 2004 and 21 trees in 2005), cumulative values of DH were also converted to binary data, i.e., "0" for $\mathrm{DH}=0$ and " 1 " for $\mathrm{DH}>0$. A generalized linear mixed model with a logit link function and binomial error structure was used to test the effects of the explanatory variables on the DH (binary data). DBH and previous infection history (binary data) were included in the model as fixed effects using PROC GLIMMIX (SAS, 2004). Year was also included as a random effect, but the variance estimate was again lower than zero. Therefore, we excluded year from the factors of the model, and tested the effects of DBH and previous infection history on DH (binary data) using logistic regression analysis with stepwise selection in PROC LOGISTIC (SAS, 2004).

\section{RESULTS}

There were four fagaceous species, Castanea crenata, $Q$. crispula, $Q$. salicina and $Q$. serrata, in the study plot (Fig. 1), and all four species are common targets for attack by $P$. quercivorus (Kobayashi and Ueda, 2005). We observed P. quercivorus flying to all four tree species in 2004 and 2005 (Yamasaki and Futai, pers. observ.), although data from species other than Q. crispula are not included in this paper.

Six trees that experienced both flying male bee-

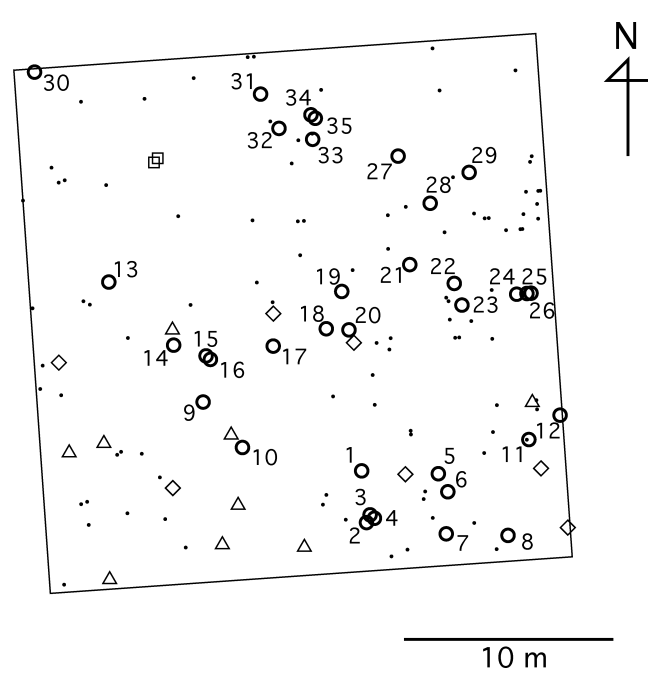

Fig. 1. Map of the study plot on a south-facing slope at the Ashiu Forest Research Station in Kyoto, Japan. Positions of trees ( $>5 \mathrm{~cm}$ in diameter at $130 \mathrm{~cm}$ aboveground) inside the study plot (solid lines) are represented as diamonds (Castanea crenata), circles (Quercus crispula), squares ( $Q$. salicina), triangles ( $Q$. serrata), and small dots (other tree species). The number next to each circle indicates the individual tree number of $Q$. crispula.

tles and beetle holes in 2004 died in either 2004 (Trees 2, 4, 21, 23, and 35) or 2005 (Tree 19) (Fig. 2). Flying male beetles were observed for a period of 1-2 months, with a clear peak during the middle of this period (Fig. 2). The abundance of flying male beetles and beetle holes in these trees was very small in 2005 compared with 2004 (Fig. 2). In addition, beetle holes were not observed in these trees in 2005, with the exception of Tree 19, which survived 2004 but died in 2005 (Fig. 2).

Ten trees that experienced both flying male beetles and beetle holes in 2004 survived until the end of 2005 (Fig. 3). Changes in NFM in 2004 (Fig. 3) were similar to patterns for the six dead trees (Fig. 2 ); i.e., we observed an intensive attack for 1-2 months with a clear peak during the middle of this period. The abundance of NFM on these trees was very small in 2005 compared with 2004 (Fig. 3). Flying male beetles were observed during only 1 week in 2005 on Trees 10, 24, 25, and 32 (Fig. 3). In 2005, no male $P$. quercivorus was captured by sticky paper traps on Trees 1 and 33 (Fig. 3), and no beetle holes were observed in any of the 10 trees (Fig. 3).

We observed a significant decrease in the annual total of NFM from 2004 to 2005 on the 16 trees (Figs. 2 and 3) bored by male P. quercivorus in 


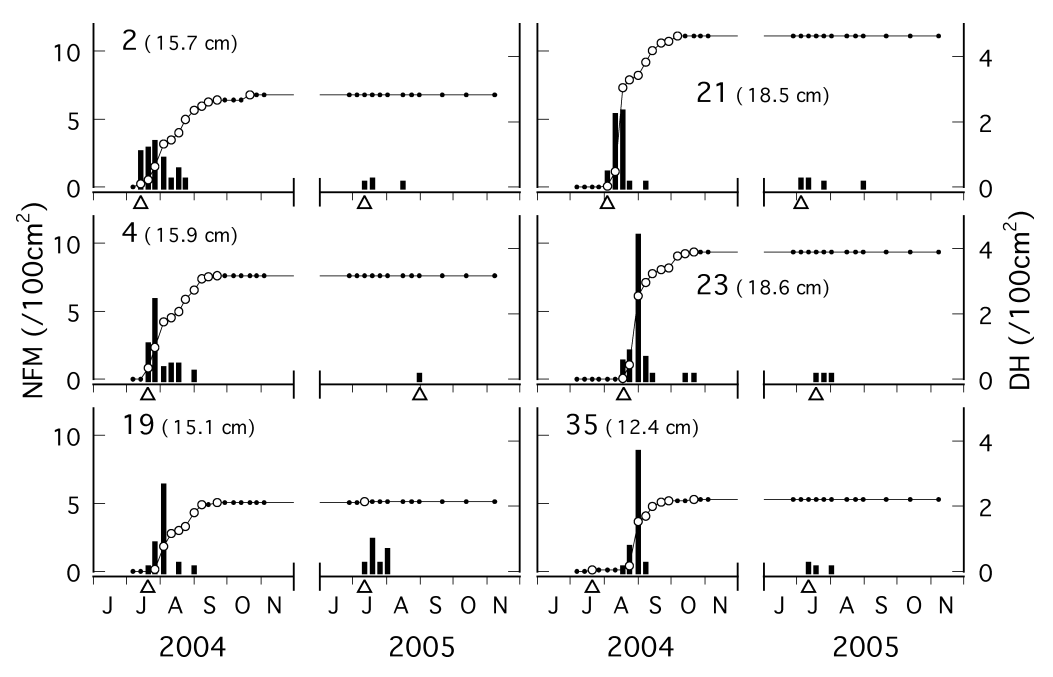

Fig. 2. Changes in the number of flying male Platypus quercivorus per $100 \mathrm{~cm}^{2}$ (black bars) and the density of beetle holes per $100 \mathrm{~cm}^{2}$ (open circles or small dots connected with solid lines) observed in six Quercus crispula trees that died in 2004 or 2005. Cumulative values of hole density over 2 years (2004 and 2005) are shown. Data for dates with increasing hole density are expressed as open circles; unchanged data are expressed as small dots. Numbers in each graph show individual tree numbers, and data in parentheses show the diameter of each tree at $130 \mathrm{~cm}$ aboveground (DBH). Triangles on $x$-axis show the dates on which flying male beetles were observed for the first time each year.

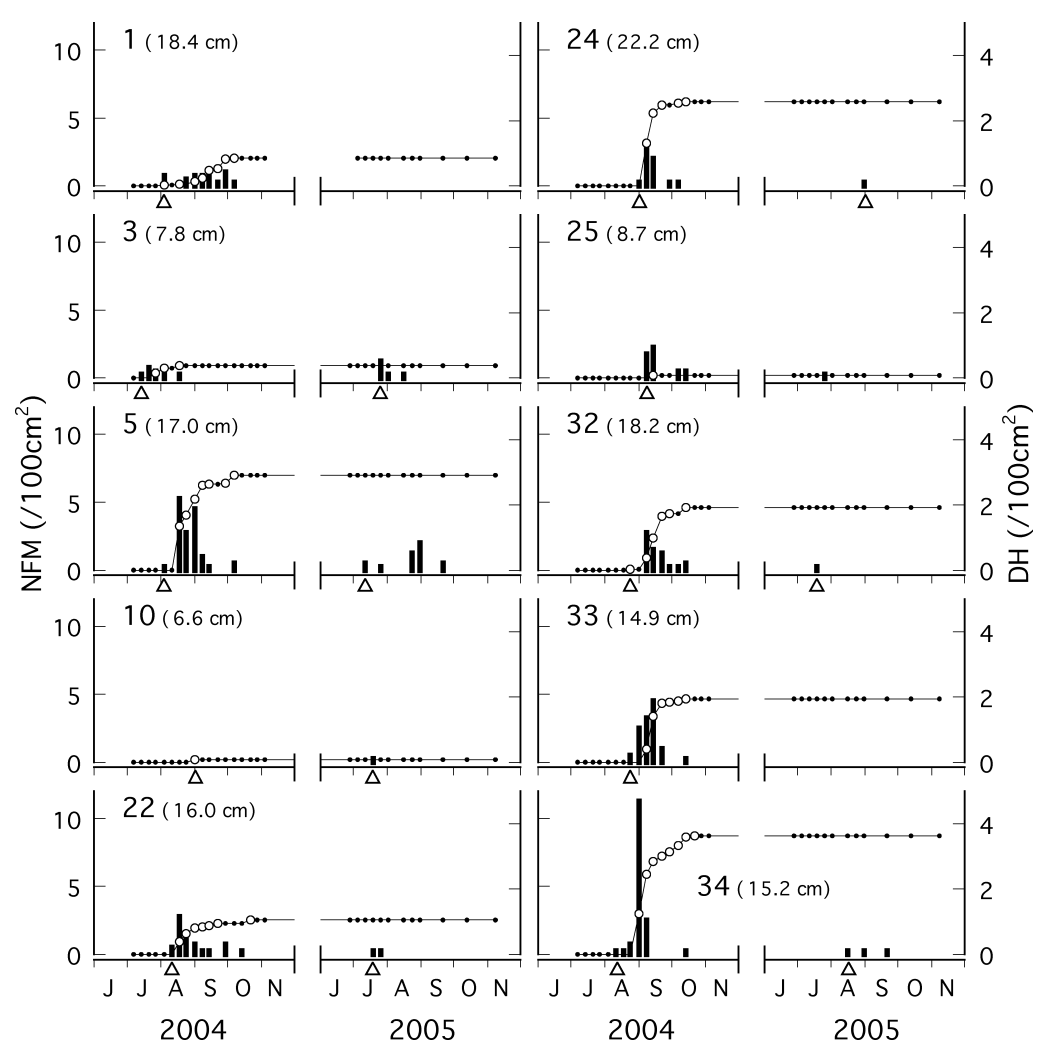

Fig. 3. Changes in the number of flying male Platypus quercivorus per $100 \mathrm{~cm}^{2}$ (black bars) and the density of beetle holes per $100 \mathrm{~cm}^{2}$ (open circles or small dots connected with solid lines) observed on Quercus crispula. Data are presented for 10 trees that exhibited beetle holes in 2004. Cumulative values of hole density over 2 years (2004 and 2005) are shown. Data for dates with increasing hole density are expressed as open circles; unchanged data are expressed as small dots. Numbers in each graph show individual tree numbers, and data in parentheses show the diameter of each tree at $130 \mathrm{~cm}$ aboveground (DBH). Triangles on the $x$-axis show the dates on which flying male beetles were observed for the first time each year. 


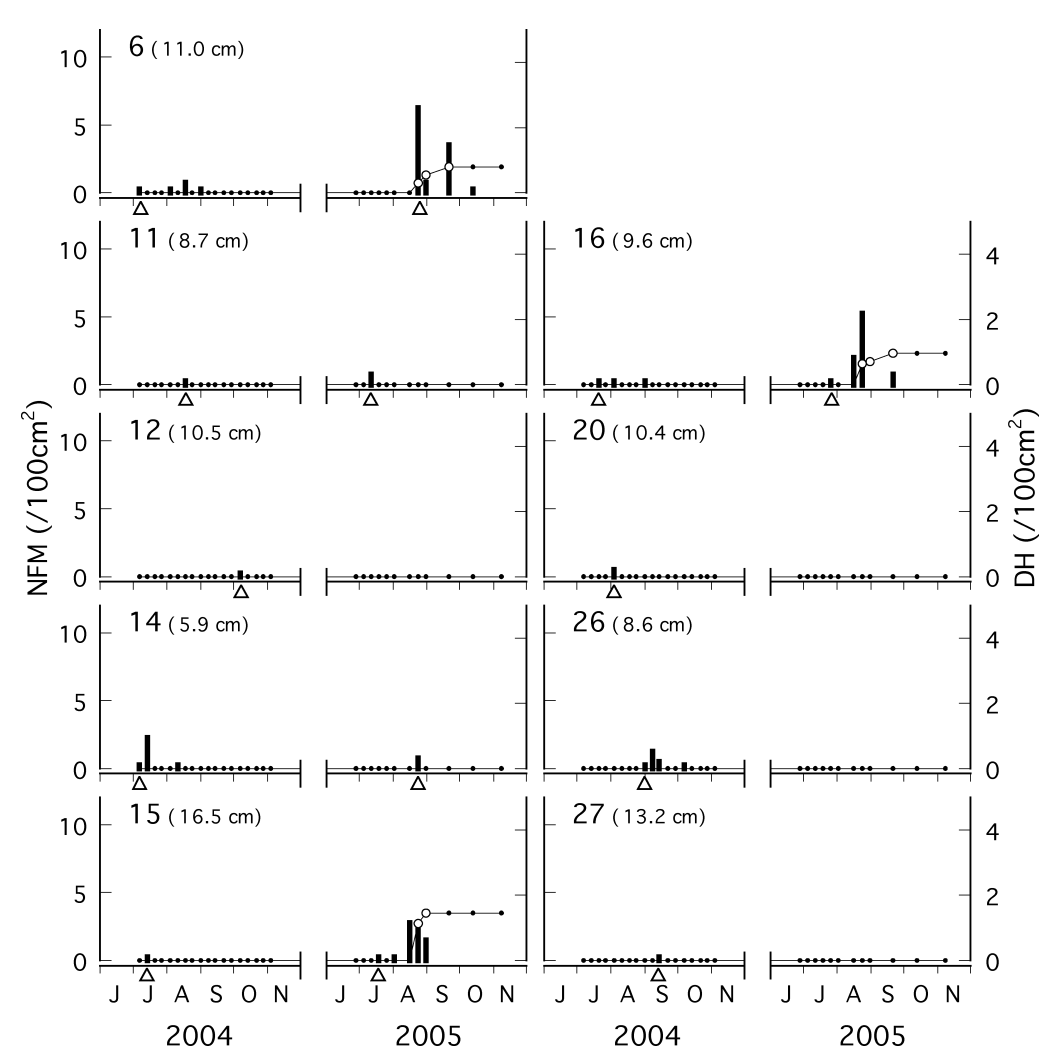

Fig. 4. Changes in the number of flying male Platypus quercivorus per $100 \mathrm{~cm}^{2}$ (black bars) and the density of beetle holes per $100 \mathrm{~cm}^{2}$ (open circles or small dots connected with solid lines). Data are presented for nine Quercus crispula that were visited by flying male beetles but exhibited no beetle holes in 2004. Cumulative values of hole density over 2 years (2004 and 2005) are shown. Data for dates with increasing hole density are expressed as open circles; unchanged data are expressed as small dots. Numbers in each graph show individual tree numbers, and data in parentheses show the diameter of each tree at $130 \mathrm{~cm}$ aboveground $(\mathrm{DBH})$. Triangles on the $x$-axis show the dates on which flying male beetles were observed for the first time each year.

2004 (Wilcoxon signed-rank test, $p<0.0001$ ).

Nine trees were visited by flying male beetles but exhibited no beetle holes in 2004 (Fig. 4). Three of the nine trees suffered intensive attacks by male P. quercivorus in 2005 (Trees 6, 15, and 16; Fig. 4) but survived until the end of 2005. We observed clear peaks in NFM on these three trees in late August, and DH increased during this period (Fig. 4); however, final values of DH were not as high as those on trees bored by male P. quercivorus in 2004 (Figs. 2 and 3).

Ten trees did not suffer from either flying male beetles or beetle holes in 2004. Of these 10 trees, eight (Trees 7, 9, 13, 17, 28, 29, 30, and 31 with $9.3,6.0,14.7,7.7,7.1,14.1,9.5$, and $9.3 \mathrm{~cm}$ in $\mathrm{DBH}$, respectively) also did not experience flying male beetles and beetle holes in 2005. Changes in NFM and DH on the other two trees (Trees 8 and 18 ), to which male $P$. quercivorus flew in 2005 , are shown in Fig. 5. Tree 8 also had beetle holes in
2005 (Fig. 5). A clear peak in NFM and an increasing $\mathrm{DH}$ were observed for Tree 8 in late July (Fig. 5).

There was no significant change in the annual total of NFM from 2004 to 2005 in the 19 trees (Figs. 4 and 5) that were not bored by male P. quercivorus in 2004 (Wilcoxon signed-rank test, $p=$ 0.3291).

Logistic regression analysis revealed a significant positive effect of DBH on the probability of male beetles flying to trees (odds ratio $=1.207, p=$ 0.0040 ). Previous infection history was not selected as an explanatory variable of the model. According to the logistic regression model, the probability of male beetle flying to trees was $>50 \%$ when DBH was $>9.0 \mathrm{~cm}$ (Fig. 6); in other words, for trees under $9.0 \mathrm{~cm}$ in $\mathrm{DBH}$, the probability of male beetles not flying to them was higher than that of male beetles flying to them.

In the logistic regression model predicting the 


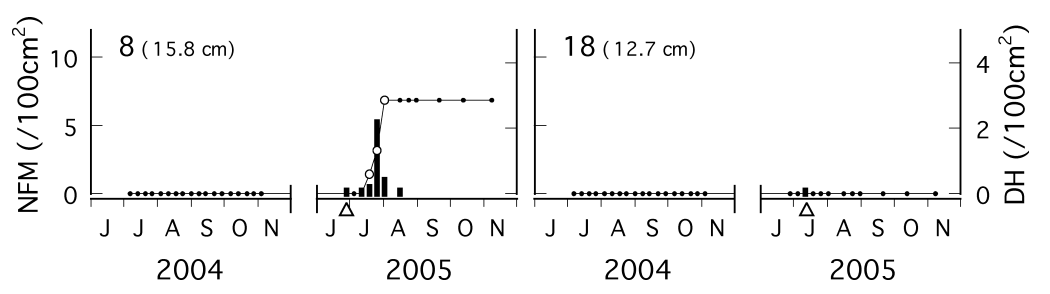

Fig. 5. Changes in the number of flying male Platypus quercivorus per $100 \mathrm{~cm}^{2}$ (black bars) and the density of beetle holes per $100 \mathrm{~cm}^{2}$ (open circles or small dots connected with solid lines) observed on two Quercus crispula with no observed activity of male beetles in 2004. Cumulative values of hole density over 2 years (2004 and 2005) are shown. Data for dates with increasing hole density are expressed as open circles; unchanged data are expressed as small dots. Numbers in each graph show individual tree numbers, and data in parentheses show the diameter of each tree at $130 \mathrm{~cm}$ aboveground (DBH). Triangles on the $x$-axis show the dates on which flying male beetles were observed for the first time each year.
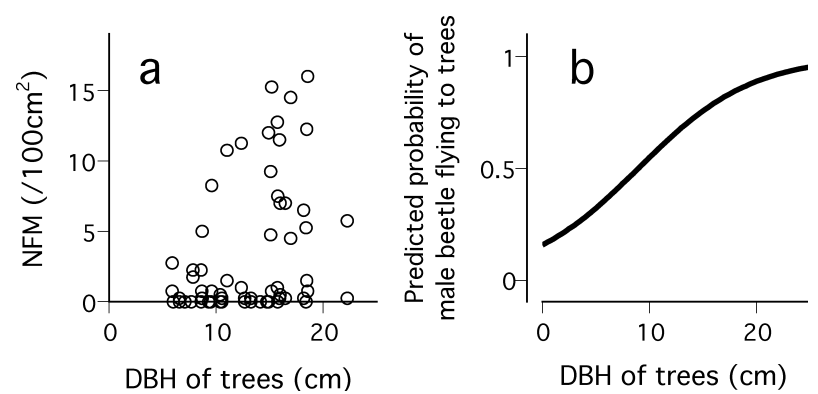

Fig. 6. (a) Relationship between the diameter of Quercus crispula at $130 \mathrm{~cm}$ aboveground (DBH) and the number of male Platypus quercivorus that flew to each tree per $100 \mathrm{~cm}^{2}$ (number of flying male beetles, NFM). Data from 2004 and 2005 (35 trees each year) were pooled. (b) The predicted probability (from a logistic regression model) of male beetles flying to trees in relation to $\mathrm{DBH}$.

probability of male beetles boring holes in trees, both DBH and previous infection history were selected as explanatory variables. $\mathrm{DBH}$ and previous infection history exhibited significant positive (odds ratio $=1.395, p=0.0054$ ) and negative (odds ratio $=0.012, p=0.0013$ ) effects, respectively, on the probability of male beetles boring holes in trees. The probability of male beetles boring holes in trees was $>50 \%$ when DBH was $>11.2 \mathrm{~cm}$ for trees with no infection history (Fig. 7). In contrast, for trees with previous infection history, the probability of male beetles boring holes was $>50 \%$ when DBH was $>24.6 \mathrm{~cm}$ (Fig. 7).

\section{DISCUSSION}

\section{Effects of DBH}

Logistic regression analysis demonstrated that the probability of male beetles flying to trees significantly increased with increases in DBH (Fig. 6). $\mathrm{DBH}$ also had a significant positive effect on the
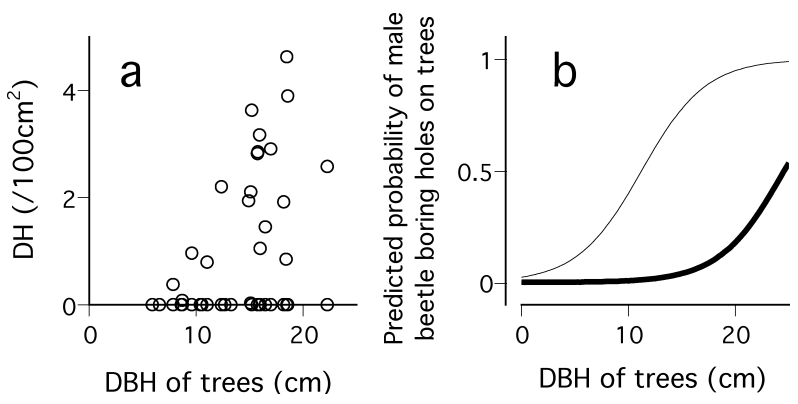

Fig. 7. (a) Relationship between the diameter of Quercus crispula at $130 \mathrm{~cm}$ aboveground (DBH) and the density of holes bored by male Platypus quercivorus per $100 \mathrm{~cm}^{2}$ (density of holes, DH). Data are presented for trees (24 trees in 2004 and 21 in 2005) with observed visits by one or more flying male beetles. (b) The predicted probability (from a logistic regression model) of male beetle boring holes in trees in relation to DBH. Data are shown for trees with (bold line) and without (thin line) beetle infection in 2004.

probability of male beetles boring holes in trees (Fig. 7). Previous study found a significant positive relationship between DBH and DH using linear regression (Kobayashi and Ueda, 2001). We analyzed tree and beetle data using logistic regression, which predicts a non-linear relationship between DBH and NFM (or DH). We also found a significant positive linear relationship between $\mathrm{DBH}$ and DH $(p=0.0031)$, but the degree of fit $\left(R^{2}=0.1865\right)$ was lower than that of logistic regression $\left(R^{2}=\right.$ 0.4139 , pseudo $R^{2}$ statistic $=0.5541$; Fig. 7$)$; therefore, the positive relationship between $\mathrm{DBH}$ and $\mathrm{DH}$ is better explained by a non-linear model.

The probabilities of male beetles flying to trees and male beetles boring holes in trees both increased with an increase in $\mathrm{DBH}$, suggesting that $P$. quercivorus disregards thinner trees of $Q$. crispula. Logistic regression analysis found a threshold value of $\mathrm{DBH}$, i.e., male beetles flying to trees oc- 
curred with $>50 \%$ probability when DBH was $>9.0 \mathrm{~cm}$ (Fig. 6). In addition, male beetles boring holes in trees occurred with $>50 \%$ probability when DBH was $>11.2 \mathrm{~cm}$ for trees with no infection history (Fig. 7). Both DBH threshold values are similar to previously observed minimum values of DBH for trees with beetle holes (Sueyoshi and Taniguchi, 1990; Sato et al., 1992; Soné et al., 1995; Shiomi and Osaki, 1997).

\section{Effects of previous infection history}

The 2-year observation of NFM and DH on $Q$. crispula trees revealed that trees with previous infection history experienced minimal flying activity of male $P$. quercivorus. Regardless of whether trees survived attacks by $P$. quercivorus, trees with previous infection history suffered very low levels of attack by beetles in the following year (Figs. 2 and 3). We observed a significant decrease in NFM from 2004 to 2005 on trees bored by male $P$. quercivorus in 2004 (Figs. 2 and 3). In addition to the small NFM, beetle holes were not observed in trees with previous infection history in 2005 , with the exception of tree 19, which died in 2005 (Figs. 2 and 3). In 2005, intensive attacks by P. quercivorus were observed on four trees (Trees 6, 8, 15, and 16) that did not exhibit beetle holes in 2004 (Figs. 4 and 5). In addition, there were no significant changes in NFM from 2004 to 2005 on trees that were not bored by male P. quercivorus in 2004 (Figs. 4 and 5). Logistic regression analysis indicated that previous infection history negatively affected the probability of male beetles boring holes in trees (Fig. 7); however, previous infection history was not selected as an explanatory variable in the model predicting the probability of male beetles flying to trees.

These results suggest that, after male $P$. quercivorus flew to trees with previous infection history (which occurred with low probability), they flew away from those trees without boring holes. Thus, the low susceptibility of $Q$. crispula with previous infection history is likely caused by the decision by male P. quercivorus not to bore holes after flying to trees. Previous studies observed holes newly bored by $P$. quercivorus in trees that had survived attacks by the beetles in the previous year (Mori et al., 1995; Inoue et al., 2000; Kobayashi, 2000; Urano, 2000). In this study, however, no newly bored holes were observed in 2005 in trees that had survived attacks by $P$. quercivorus in 2004, irrespective of the density of 2004 holes (Fig. 3). This difference could be explained by the forest condition in this study. In this research station, boring activity of P. quercivorus began to be observed in 2004, and many fagaceous trees may have remained uninfected by the beetles in 2005; therefore, it is probable that $P$. quercivorus showed a marked preference for uninfected trees. The fact that four trees (Trees 6, 8, 15 and 16; Figs. 4 and 5), in which many holes newly bored by male $P$. quercivorus were observed in 2005, were uninfected in 2004 supports this idea.

\section{Proximate causes for host selection}

Thinner trees may not be heavily attacked by P. quercivorus because of resource constraints for constructing long galleries necessary for successful reproduction (Hijii et al., 1991). During their long coexistence with host trees, P. quercivorus may have been selected to avoid thinner trees with narrow spaces. Our results also suggest that $P$. quercivorus disregards thinner trees; therefore, space constraints for gallery construction are a likely ultimate, rather than proximate, cause of host selection by $P$. quercivorus.

In conifer bark beetles, visual (Campbell and Borden, 2006) and olfactory cues (e.g., tree volatiles) (Zhang and Schlyter, 2004) were proposed as proximate causes for their host selection. Previous field studies reported an increase in the number of Dendroctonus pseudotsugae beetles attracted to pheromone-baited traps when the volatiles of their own host trees were used as the kiromone (Pureswaran and Borden, 2005). Furthermore, Byers et al. (2004) reported a significant reduction in the number of Pityogenes bidentatus beetles attracted to pheromone-baited traps when the volatiles of non-host trees were used as the kiromone. Thus, tree volatiles of non-host trees may serve as chemical repellents in some cases of host selection by bark beetles.

We hypothesize that $P$. quercivorus selects thick trees that emit certain types of chemicals. Platypus quercivorus engages in chemical communication among conspecifics, and aggregation pheromones are used in mass attacks on trees (Ueda and Kobayashi, 2001a; Kashiwagi et al., 2006; Tokoro et al., 2007). Chemical cues from the host trees to $P$. quercivorus may also exist, which may help the 
beetles to select their own host trees. Moreover, our observations of $P$. quercivorus leaving after flying to trees with previous infection history indicated that the beetles can distinguish them from trees with no infection history, prior to boring holes. This behavior may be driven by repellent chemicals emitted from the host trees and/or conspecifics. Further research into the response of $P$. quercivorus to volatiles emitted from their own host trees of various sizes and of various infection histories is thus needed.

\section{ACKNOWLEDGEMENTS}

We thank the entire staff of the Ashiu Forest Research Station, Field Science Education and Research Center at Kyoto University, for enabling us to conduct this research. We are indebted to Dr. D. Fujiki of the Museum of Nature and Human Activities in Hyogo, Mr. Y. Takeuchi of the Laboratory of Environmental Mycoscience at Kyoto University, and Mr. Y. Ito, Mr. R. Harada and Mrs. M. Harada for their assistance with field work. We also thank all members of the Laboratory of Forest Biology at Kyoto University for their help and advice during our study. This research was supported by Grantsin-Aid for Scientific Research from the Ministry of Education, Culture, Sports, Science and Technology (No. 15380106) and the 21st Century COE Program of Kyoto University: "Innovative Food and Environmental Studies Pioneered by Entomomimetic Sciences" from the Japan Society for the Promotion of Science.

\section{REFERENCES}

Byers, J. A., Q.-H. Zhang and G. Birgersson (2004) Avoidance of nonhost plants by a bark beetle, Pityogenes bidentatus, in a forest of odors. Naturwissenschaften 91: 215-219.

Campbell, S. A. and J. H. Borden (2006) Integration of visual and olfactory cues of hosts and non-hosts by three bark beetles (Coleoptera: Scolytidae). Ecol. Entomol. 31: 437-449.

Hijii, N., H. Kajimura, T. Urano, H. Kinuura and H. Itami (1991) The mass mortality of oak trees induced by Platypus quercivorus (Murayama) and Platypus calamus Blandford (Coleoptera: Platypodidae): the density and spatial distribution of attack by the beetles. J. Jpn. For. Soc. 73: 471-476.

Inoue, M., S. Nishigaki and N. Nishi (2000) Attack by the oak borer, Platypus quercivorus, to living oak trees. Appl. For. Sci. 9(1): 127-131 (in Japanese with English summary).

Ito, S. and T. Yamada (1998) Distribution and spread of the mass mortality of oak trees. J. Jpn. For. Soc. 80: 229232 (in Japanese).

Ito, S., T. Kubono, N. Sahashi and T. Yamada (1998) Associated fungi with the mass mortality of oak trees. J. Jpn. For. Soc. 80: 170-175 (in Japanese with English summary).
Kashiwagi, T., T. Nakashima, S. Tebayashi and C. S. Kim (2006) Determination of the absolute configuration of quercivorol, $(1 S, 4 R)$ - $p$-menth-2-en-1-ol, an aggregation pheromone of the ambrosia beetle Platypus quercivorus (Coleoptera: Platypodidae). Biosci. Biotechnol. Biochem. 70: 2544-2546.

Kinuura, H. and M. Kobayashi (2006) Death of Quercus crispula by inoculation with adult Platypus quercivorus (Coleoptera: Platypodidae). Appl. Entomol. Zool. 41: 123-128.

Kirkendall, L. R. (1983) The evolution of mating systems in bark and ambrosia beetles (Coleoptera: Scolytidae and Platypodidae). Zool. J. Linn. Soc. 77: 293-352.

Kobayashi, M. (2000) The boring to logs of several broadleaf trees by Platypus quercivorus (Murayama). Appl. For. Sci. 9(2): 99-103 (in Japanese with English summary).

Kobayashi, M. and M. Hagita (2000) Process of mass mortality of oak trees and capture of Platypus quercivorus Murayama (Coleoptera: Platypodidae). Appl. For. Sci. 9(1): 133-140 (in Japanese with English summary).

Kobayashi, M. and S. Shibata (2001) Infestation of Platypus quercivorus (Murayama) (Coleoptera: Platypodidae) at a newly damaged forest by the beetle (I): investigation in Maizuru, Kyoto Prefecture. Appl. For. Sci. 10(2): 73-78 (in Japanese with English summary).

Kobayashi, M. and A. Ueda (2001) Infestation of Platypus quercivorus (Murayama) (Coleoptera: Platypodidae) at newly damaged forests by the beetle (II): investigation in Wachi and Keihoku, Kyoto Prefecture. Appl. For. Sci. 10(2): 79-84 (in Japanese with English summary).

Kobayashi, M. and A. Ueda (2005) Wilt disease of Fagaceae trees caused by Platypus quercivorus (Murayama) (Coleoptera: Platypodidae) and the associated fungus: aim is to clarify the damage factor. J. Jpn. For. Soc. 87: 435-450 (in Japanese with English summary).

Kobayashi, M., A. Nozaki and H. Kinuura (2004) Influence of sap on reproduction of Platypus quercivorus (Murayama) (Coleoptera: Platypodidae). Appl. For. Sci. 13: 155-159 (in Japanese).

Kubono, T. and S. Ito (2002) Raffaelea quercivora sp. nov. associated with mass mortality of Japanese oak, and the ambrosia beetle (Platypus quercivorus). Mycoscience 43: 255-260.

Mori, T., K. Soné, M. Ide and H. Umata (1995) Infestation on standing oak trees by the oak borer, Platypus quercivorus (Murayama) (Coleoptera: Platypodidae) in the Takakuma Experimental Forest, Kagoshima University. Bull. Kagoshima Univ. For. 23: 23-32 (in Japanese with English summary).

Nishigaki, S., M. Inoue and N. Nishimura (1998) The relationship between the number of boring by Platypus quercivorus and the wood of water content in the mass mortality of oak trees. Appl. For. Sci. 7: 117-120 (in Japanese with English summary).

Pureswaran, D. S. and J. H. Borden (2005) Primary attraction and kairomonal host discrimination in three species of Dendroctonus (Coleoptera: Scolytidae). Agr. Forest Entomol. 7: 219-230. 
Saito, S., H. Nakamura, N. Miura, K. Mikawa and K. Onose (2001) Process of mass oak mortality and the relation to Platypus quercivorus and its specific fungus. J. Jpn. For. Soc. 83: 58-61 (in Japanese with English summary).

SAS (2004) SAS/STAT 9.1 User's Guide. SAS Institute, North Carolina, USA.

Sato, S., N. Yoshida and K. Okabe (1992) The injuries of broad leaved trees by Platypus quercivorus (Platypodidae, Coleoptera) in Aya national forest, Miyazaki prefecture. Trans. Kyushu Branch Jpn. For. Soc. 45: 133-134 (in Japanese).

Shiomi, S. and S. Osaki (1997) Mass mortality of Quercus serrata and Q. mongolica in Hyogo Prefecture. Appl. For. Sci. 6: 197-198 (in Japanese).

Soné, K., T. Ushijima, T. Mori, M. Ide and H. Umata (1995) Incidence and spatial distribution pattern of trees infested by the oak borer, Platypus quercivorus (Murayama) (Coleoptera: Platypodidae), in a stand. Bull. Kagoshima Univ. For. 23: 11-22 (in Japanese with English summary).

Sueyoshi, M. and A. Taniguchi (1990) Studies on the Japanese ambrosia-beetles, Platypus quercivorus (I): Geographical distributions and actual conditions of damage. Trans. Kyushu Branch Jpn. For. Soc. 43: 153-154 (in Japanese).

Tokoro, M., M. Kobayashi, S. Saito, H. Kinuura, T. Nakashima, E. Shoda-Kagaya, T. Kashiwagi, S. Tebayashi,
C. S. Kim and K. Mori (2007) Novel aggregation pheromone, $(1 S, 4 R)$ - $p$-menth-2-en-1-ol, of the ambrosia beetle, Platypus quercivorus (Coleoptera: Platypodidae). Bull. For. For. Prod. Res. Inst. 6: 49-57.

Ueda, A. and M. Kobayashi (2001a) Aggregation of Platypus quercivorus (Murayama) (Coleoptera: Platypodidae) on oak logs bored by males of the species. J. For. Res. 6: 173-179.

Ueda, A. and M. Kobayashi (2001b) Seasonal change of number of Platypus quercivorus (Murayama) and P. calamus Blandford (Coleoptera: Platypodidae) landing on living trees. J. Jpn. For. Soc. 83: 77-83 (in Japanese with English summary).

Urano, T. (2000) Relationships between mass mortality of two oak species (Quercus mongolica Turcz. var. grosseserrata Rehd. et Wils. and Q. serrata Thunb.) and infestation by and reproduction of Platypus quercivorus $(\mathrm{Mu}-$ rayama) (Coleoptera: Platypodidae). J. For. Res. 5: 187193.

Yamasaki, M., A. Iwatake and K. Futai (2007) A low Platypus quercivorus hole density does not necessarily indicate a small flying population. J. For. Res. 12: 384-387.

Zhang, Q.-H. and F. Schlyter (2004) Olfactory recognition and behavioural avoidance of angiosperm nonhost volatiles by conifer-inhabiting bark beetles. Agr. Forest Entomol. 6: 1-19. 